\title{
Memorial Chico Science: o Manguebeat como patrimônio cultural da cidade do Recife
}

\author{
Chico Science Memorial: The Manguebeat \\ Cultural Scene Transformed in Heritage in Recife
}

\section{Esdras Lima Oliveira ${ }^{1}$}

DOI: $10.19177 /$ memorare.v8e12021265-285

\begin{abstract}
Resumo: O Manguebeat, cena cultural dos anos 1990 que teve certa repercussão nacional e internacional, tornou-se a partir dos anos 2000, especialmente com a chegada do Partido dos Trabalhadores ao poder na cidade, parte importante do discurso cultural na capital pernambucana. Dessa maneira, uma série de políticas públicas passaram a usar o legado simbólico da cena na construção de lugares de memória e de símbolos para a cidade, em um movimento precoce de construção de uma seleção de ícones que passou por um processo de patrimonialização. Devido a esse contexto, o Memorial Chico Science (MSC), hoje fechado por conta da pandemia de COVID-19, foi construído em homenagem ao cantor e principal nome da cena, morto em 1997, como espaço não apenas de memória, mas de construção cultural a partir dos preceitos postos pelas bandas na já distante década de 1990 .

Palavras-chave: Políticas públicas. Lugares de Memória. Patrimonalização do Manguebeat.
\end{abstract}

\begin{abstract}
The Manguebeat was a cultural scene from the 1990s in the city of Recife that had a certain national and international repercussion and became from the 2000s, especially with the arrival of the Workers' Party to power in the city, as an important part of the cultural discourse in the capital of Pernambuco. Thus, a series of public policies began to use the symbolic legacy of the scene in the construction of places of memory and symbols for the city in an early process of building a selection of icons that went through a process of patrimonialization. The Chico Science Memorial, now closed because of the COVID-19 pandemic, was built in honor of the singer and the main name of the scene, who died in 1997, as a space not only for memory, but for cultural construction based on the precepts put by the bands in the distant 1990s. Keywords: Public policy. Places of Memory. Heritage of the Manguebeat.
\end{abstract}

\footnotetext{
${ }^{1}$ Doutor em História pela Universidade Federal de Uberlândia; Mestre em História Social da Cultura Regional pela Universidade Federal Rural de Pernambuco, Especialista em História das Artes e das Religiões pela mesma instituição e licenciado em História pela Faculdade de Formação de Professores de Nazaré da Mata - Universidade de Pernambuco. Atualmente é professor do Instituto Federal de Rondônia - Campus Guajará-Mirim. esdras.oliveira@ifro.edu.br.
} 


\section{Lugares de memória e a patrimonialização do Manguebeat}

Parte importante de um conjunto de ações que se utilizaram do discurso cultural do Manguebeat e de seus signos foi sendo construída na primeira década deste século, notadamente nos mandatos do PT à frente da Prefeitura do Recife. Nessa linha, uma série de elementos foram criados na capital pernambucana como referências para demarcar uma determinada visão sobre a cidade e servirem de pontos de referência para a construção de um discurso público sobre os seus espaços e as políticas públicas.

Nesse sentido, o discurso da história implica na reconstrução sempre problemática e incompleta do que não existe mais. Dessa maneira, uma estátua ou uma instalação em uma das mais antigas ruas do Recife, ao lado de importantes marcos espaciais; o nome de um túnel, por onde passam milhares de carros todos os dias na região central e a criação de um local mantido pelo poder público para rememorar aspectos da história do Manguebeat e do seu principal nome são, sem dúvida, lugares de memória.

Tais lugares (que englobam arquivos, museus, cemitérios, coleções, tratados, monumentos, santuários, dentre outros) são testemunhos de uma era diferente, que aspira, de certo modo, à eternidade. Em muitos casos, esses objetos promovem sacralizações de momentos já dessacralizados. Na ótica de Pierre Nora,

Os lugares de memória nascem e vivem do sentimento que não existe memória espontânea, que é preciso criar arquivos, que é preciso manter os aniversários, organizar as celebrações, pronunciar as honras fúnebres, estabelecer contratos, porque estas operações não são naturais [...]. Se vivêssemos verdadeiramente as lembranças que eles envolvem, eles seriam inúteis. E se, em compensação, a história não se apoderasse deles para deformá-los, transformá-los, sová-los e petrificá-los, eles não se tornariam lugares de memória. É este vai-e-vem que os constitui: momentos de história arrancados do movimento de história, mas que lhe são devolvidos (NORA, 1993, p. 13).

Por isso, o autor complementa, afirmando que, o que chamamos de memória é "a constituição gigantesca e vertiginosa do estoque material daquilo que nos é impossível lembrar, repertório insondável daquilo que poderíamos ter necessidade de lembrar" (NORA, 1993, p. 15). Com o processo de evaporação da memória tradicional, devido, sobretudo, à rapidez da velocidade da informação e ao crescimento da sensação de presentismo, nós nos sentimos compelidos a criar espaços para armazenar ou representar os vestígios dessa memória. Dessa forma, a materialização da memória dilatou-se, ganhou centralidade, movida pelo desejo, nas sociedades contemporâneas, de salvaguardar o que se considera que deva ser preservado. Logo se vê que algo alterou a relação com o passado, e tal fato é marca do novo regime de historicidade, fincado no presente. Observando o caso francês, que pode, evidentemente, ser estendido ao Brasil, Hartog pondera: "Ao longo desses anos, a onda patrimonial, em sintonia com a da memória, aumenta cada vez mais até tender a esse limite que seria 'todo o patrimônio'. Assim como se anunciam ou se reivindicam memórias de tudo, tudo seria patrimônio ou suscetível de tornar-se. A mesma inflação 
parece reinar. A patrimonialização ou museificação venceu, aproximando-se cada vez mais do presente" (HARTOG, 2013, p. 233).

Não deixa de ser interessante constatar que o Manguebeat, com pouco mais de vinte e cinco anos, com bandas ainda ativas, passe a ser alçado à condição de patrimônio do Estado. No caso, um patrimônio imaterial que, diferentemente do material, se situa no campo do simbólico, das práticas e saberes, e que tem adquirido centralidade nas convenções internacionais sobre cultura e nas políticas culturais dos países, principalmente os periféricos.

Esse fenômeno de valorização do passado, de elaboração de grandes comemorações e de criação de marcos para a lembrança associa-se aos já mencionados lugares de memória, cuja função, conforme Nora, é "parar o tempo, é bloquear o trabalho do esquecimento, fixar um estado de coisas, imortalizar a morte, materializar o imaterial [...] prender o máximo de sentido num mínimo de sinais" (NORA, 1993, p. 22). Além disso,

\begin{abstract}
Mesmo um lugar de aparência puramente material, como um depósito de arquivos, só é lugar de memória se a imaginação o investe de aura simbólica. Mesmo um lugar puramente funcional, como um manual de aula, um testamento, uma associação de antigos combatentes, só entra na categoria se for objeto de um ritual. Mesmo um minuto de silêncio, que parece o extremo de uma significação simbólica, é, ao mesmo tempo, um corte material de uma unidade temporal e serve, periodicamente, a um lembrete concentrado de lembrar. Os três aspectos coexistem sempre [...]. É material por seu conteúdo demográfico; funcional por hipótese, pois garante ao mesmo tempo a cristalização da lembrança e sua transmissão; mas simbólica por definição visto que caracteriza por um acontecimento ou uma experiência vivida por pequeno número uma maioria que deles não participou (NORA, 1993, p. 21-22).
\end{abstract}

François Hartog, em Regimes de historicidade, assinala que se assiste a um processo acelerado de presenteísmo, ou seja, o presente tem ditado os processos da memória, em ritmo cada vez mais acentuado no atual regime de historicidade. E a criação de lugares de memória assume, nesse contexto, papel fundamental. De acordo com o historiador, por volta de finais do século XVII surgiu um regime de historicidade moderno, que abriu espaço ao longo do século XX, para um presenteísmo cada vez mais marcante. Se antes imperava a utopia do futuro, agora se afirma o apego, cada vez mais arraigado, aos processos focados no hoje.

Nas circunstâncias dos tempos atuais, o patrimônio é o alter ego da memória. Não se trata apenas de um gosto pelo passado, mas um impulso com vistas à salvaguarda e à patrimonialização, inclusive, de elementos presentes. A aceleração da informação em tempo real e a tecnologia invadindo cada vez mais o nosso dia a dia levam a certo medo do esquecimento que passa a permear determinados setores de nossa sociedade. Tanto que Andreas Huyssen se pergunta: "Para onde quer que se olhe, a obsessão contemporânea pela memória nos debates públicos se choca com um intenso pânico frente ao esquecimento, e poder-se-ia perfeitamente perguntar qual dos dois vem em primeiro lugar. É o medo do esquecimento que dispara o desejo de lembrar ou é, talvez, o contrário?" (HUYSSEN, 2000, p. 19). 
Esse é um processo que Joël Candau chama de "iconorréia contemporânea" (CANDAU, 2016, p. 111). De acordo com esse antropólogo, "o mundo moderno produz trações e imagens a um nível jamais visto na história das sociedades humanas, estando em parte submisso às 'ideologias de segurança' da história e da memória que conduzem a tudo conservar, tudo armazenar, musealizar a totalidade do mundo conhecido e, por outro lado, continuando a produzir mais informações e mensagens" (CANDAU, 2016, p. 111).

Com o fim da Segunda Guerra, especialmente na Europa e nos países que participaram do conflito, começaram a ser construídos espaços, lugares de memória, para a lembrança das atrocidades cometidas. (HUYSSEN, 2000). Dessa maneira, como uma memória espacializada e seletiva, esses locais servem para lembrar os milhões de soldados mortos, as vítimas do holocausto (que envolvem, além de judeus, ciganos, homossexuais, testemunhas de Jeová e militantes de esquerda ou contrários aos regimes fascistas) proliferaram pelo mundo, sobretudo em grandes cidades.

Guardadas as diferenças, o Brasil viveu um processo similar, com a criação de alguns memoriais bem conhecidos, como o dedicado a Juscelino Kubitschek, na capital federal (CEBALLOS, 2005), o Memorial do Imigrante, que funciona na antiga Hospedaria do Imigrante em São Paulo e que possibilita acesso a informações sobre milhares de pessoas que transitaram por lá e se tornaram parte da cidade. Outro exemplo é o Parque Memorial Zumbi dos Palmares, localizado na Serra da Barriga, no Estado de Alagoas. Foram erguidos marcos na paisagem para a lembrança do quilombo que existiu ali, e o local converteu-se numa referência de grande importância para o movimento negro brasileiro e sobre a resistência da população negra escravizada (Cf.: BRASIL, PARQUE MEMORIAL ZUMBI DOS PALMARES).

Paralelamente, vários países, entre eles novamente o nosso, que sofreram com processos ditatoriais ou tragédias humanitárias, se puseram a constituir comissões para reavivar memórias e formar acervos para a posteridade. Em meio a isso, ao longo das últimas duas décadas assistimos o surgimento de algumas Comissões da Verdade integradas a todo um esforço, de parcelas do poder público e da sociedade civil, de exigir reparação dos crimes da ditadura pós-1964. Surgiram, então, contundentes relatórios oficiais sobre perseguições políticas, torturas, assassinatos e desaparecimentos. A Comissão Nacional da Verdade, instalada em 2012, possibilitou o acesso a um amplo cabedal de documentação apta a permitir um olhar mais penetrante sobre as agruras perpetradas pelo regime ditatorial que se estendeu de 1964 a 1985 (ELIAS, 2018).

Abrindo um parêntese, convém assinalar que o campo da memória não é exatamente uma novidade para a História. Durante certo tempo houve, é bem verdade, uma separação rígida entre ambos. A memória era tomada como algo perigoso, pelos laços que a prendiam à subjetividade, para uma disciplina que visava afirmar seu estatuto científico com base em um aparato rigoroso de pesquisa, apegada a documentos escritos. Mexer com a subjetividade parecia uma forma de tornar o discurso rarefeito, sem defender-se de falsificações ou escamoteamentos do passado. Daí, como evidenciou Jacques Le Goff 
(1990) em "História e memória", o distanciamento que se cavou entre elas.

No entanto, no decorrer da segunda metade do século XX, a memória passou a ganhar cada vez mais espaço nas instituições do Estado e nos meios de comunicação. Houve inclusive um incremento cada vez maior nas instituições de registro e conservação do material oriundo de pesquisas de História Oral (Cf.: ALBERTI, in: PINSKY, 2015). Isso transbordou do simples interesse de grupos específicos, como sindicatos ou movimentos sociais, para o espaço acadêmico, notadamente da década de1980 em diante, registrando-se o surgimento de eventos, disciplinas e a formulação de uma metodologia mais clara para lidar com tal objeto. Em suma, a História Oral aproximou a História da memória. Simultaneamente, a tecnologia desempenhou uma função especialíssima no enquadramento da memória e no ato de lembrar ou esquecer. Com os novos experimentos da informática, abriu-se a era da memória computacional, memória das máquinas, que funcionam como "anexos" do cérebro, acelerando processos.

Como salienta Hartog, "o patrimônio é a reunião dos semióforos criada por uma sociedade, em um dado momento (e por um momento). Eles traduzem então o tipo de relação que uma sociedade decide estabelecer com o tempo. 0 patrimônio torna visível, expressa uma certa ordem do tempo, na qual a dimensão do passado conta. Trata-se, porém, de um passado do qual o presente não pode ou não quer se desligar completamente" (HARTOG, 2013, p. 197).

Efetivamente, a escolha, por parte do poder público, de marcos, de signos ou de semióforos para expor no espaço da cidade implica certa intencionalidade e materializa a visão de mundo dos governantes e, possivelmente, de parte do tecido social que chancelou a escolha daqueles dirigentes. Foi o que se viu, no caso do frevo, por exemplo, inclusive com a criação de um espaço de memória, o Paço do Frevo, e, entrando naquilo que aqui nos interessa mais de perto, o Manguebeat.

De certa forma, isso foi facilitado por algum grau de proximidade existente entre os mangueboys e a política institucional, particularmente o Partido dos Trabalhadores (PT). Os antecedentes dessa aproximação remontam pelo menos a 1992. Nas eleições desse ano para a Prefeitura do Recife, o jingle do então candidato Humberto Costa foi elaborado por alguns dos membros do Manguebeat, e depois ele se tornaria parte de uma das suas mais conhecidas canções. Os autores eram ninguém menos do que Fred Zero Quatro e Chico Science. 0 jingle baseado na música "Rios pontes e overdrives", citava bairros da cidade, como numa espécie de caminhada acelerada pelo Recife: "É Macaxeira, Imbiribeira, Bom Pastor, é o Ibura, Ipsep, Torreão, Casa Amarela/ Boa Viagem, Jenipapo, Bonifácio, Santo Amaro, Madalena, Boa Vista, Dois Irmãos / é Cais do Porto, é Caxangá, é Brasilite, Beberibe, é CDU, Capibaribe, é o Centrão/ eu falei!" (SCIENCE, 1994).

No começo deste século, Fred Zero Quatro e Renato Lins assumiram papel importante na área cultural quando o PT governou a cidade entre 2002 2012. Inicialmente Zero Quatro presidiu o Conselho de Cultura recifense, durante a transição do governo de Roberto Magalhães para o de João Paulo. Na administração de João da Costa, entre 2009 e 2012, Renato Lins foi o titular da Secretaria da Cultura, 
substituindo João Roberto Peixe, que havia sido chamado para ocupar uma das secretarias do Ministério da Cultura. Até hoje os dois mangueboys são simpáticos ao partido, como se nota nas postagens nas redes sociais favoráveis aos seus candidatos.

Nos três mandatos petistas, o Mangue foi alçado a relevante referência simbólica e material nas políticas implementadas. Nesse passo, o Partido dos Trabalhadores utilizou-se de parte dos símbolos criados pelo Manguebeat como forma de legitimar suas políticas. Nas próximas páginas, analisaremos a relação entre o PT e a cena mangue através de leis e comendas concedidas e a construção de dois lugares de memória criados pela Prefeitura do Recife em conexão direta com os simbolismos da figura de Chico Science e do Manguebeat.

\section{A transformação do Manguebeat em patrimônio: o Memorial}

Em um texto curto, de não mais que quatro linhas, a Lei ํㅜ 13.853, promulgada pelo então governador Eduardo Campos (do Partido Socialista Brasileiro) em 19 de agosto de 2009, considera o Manguebeat patrimônio cultural imaterial do estado de Pernambuco (PERNAMBUCO, Lei № 13.853, 2009). De autoria do deputado petista Sérgio Leite, o instrumento elevou-o ao mesmo patamar de coisas tão díspares como o bolo de rolo, a feira de Caruaru e o frevo. Em entrevista ao site da Assembleia Legislativa do Estado de Pernambuco (Alepe), Leite argumentou que: "o Manguebeat trata também da biodiversidade do manguezal como ecossistema associado à fusão de estilos, locais e globais, capaz de tornar a cena cultural de Pernambuco tão rica quanto sua situação geográfica. Gêneros como o rock, o reggae e hip-hop se misturaram ao maracatu, ao coco e ao samba" (PERNAMBUCO, 8/12/2009).

Essa fala condensa parte do discurso que o Manguebeat construiu sobre si e que consta no mencionado texto Caranguejos com cérebro ou de canções da Chico Science \& Nação Zumbi e Mundo Livre S/A. Nela sobressai a "biodiversidade" como alegoria da diversidade cultural e a "fusão de estilos" como marca da musicalidade das bandas. O deputado lembrou ainda que, "por sua importância histórica, além de influenciar expressões artísticas como o cinema, a moda e as artes plásticas, no Brasil e no mundo, [o Manguebeat] contribui na difusão do estilo nacional" (PERNAMBUCO, Lei № 13.853, 2009).

É interessante destacar, nesse pronunciamento, o uso da expressão "importância histórica". A lei foi criada em 2009, menos de vinte anos depois que se ouviram os primeiros acordes das bandas e dos eventos que impulsionaram sua inserção no cenário musical pernambucano. De mais a mais, com exceção de Chico Science, todos os seus participantes estão vivos. No entanto, para defender a elevação do Manguebeat à categoria de patrimônio, o parlamentar recorreu a um discurso sobre o tempo, no caso, a história. Daí que, passada pouco mais de uma década, uma manifestação cultural tornou-se parte do rol de patrimônios culturais do estado.

Já o adjetivo imaterial segue a tendência do alargamento do conceito de patrimônio que se desenvolveu principalmente desde os anos 80, sendo apropriado pela Unesco, órgão das Nações Unidas ligado à educação e cultura e que promove a proteção a áreas de relevância 
cultural, arquitetônica e histórica. A concepção de patrimônio - que durante séculos se prendeu à conservação de prédios a "pedra e cal", igrejas, castelos, palacetes e casas das classes mais altas de países centrais - foi dilatada especialmente nas cartas patrimoniais da ONU que dão base jurídica para toda legislação do gênero dos países signatários da Unesco. Sob tal ótica, o patrimônio imaterial é aquele vinculado a saberes e práticas específicos de algum lugar, ou seja, são identificados com um espaço e um grupo social específico (Cf.: CHOAY, 2006).

O Manguebeat também recebeu uma distinção, a Ordem do Mérito Cultural, concedida pelo Ministério da Cultura. Poucos dias antes da sessão solene de concessão dessa honraria, o deputado federal petista Paulo Rubem se pronunciou na Câmara dos Deputados:

E me refiro especialmente ao Movimento Mangue Beat, ainda desconhecido para alguns, mas que para Pernambuco, para grande parte do Nordeste, para vários setores da música do Brasil e mesmo do mundo representa uma das vanguardas da fusão rítmica, poética, com a criação de uma nova interpretação da vinculação do rock com a genuína música popular, os ritmos da cultura popular pernambucana, nordestina. Perdemos Chico Science, mas ainda temos, representando a origem dessa cultura, do Movimento Mangue Beat, bandas como Mundo Livre S/A liderada pelo jornalista Fred Zero Quatro, até pouco tempo presidente do Conselho Municipal de Cultura da cidade do Recife -, Nação Zumbi, entre outras que retiraram do gueto as manifestações da ciranda, do coco-deroda, do maracatu, do cavalo-marinho e do reisado, espalhadas por várias cidades nordestinas (BRASIL, 10/11/2018).

No pronunciamento do deputado, destacaram-se pontos-chave do discurso do Manguebeat sobre si e sobre a cultura popular, que nos dispensamos de reiterar aqui, porque já os mencionamos anteriormente. E mais: a outorga dessa distinção deu-se em 8 de novembro de 2005, no Palácio do Planalto, em Brasília, numa cerimônia festiva marcada pela grande quantidade de agraciados ${ }^{2}$, com direito à presença de Luis Inácio Lula da Silva, presidente da República, e de Gilberto Gil, ministro da Cultura, que então discursaram. Isso equivaleu, a rigor, à legitimação institucional, em escala nacional, do Manguebeat, que, sob vários aspectos, já vinha obtendo reconhecimento internacional.

Independentemente disso, num balanço sobre o que se passou, seja quanto à patrimonialização do Manguebeat, seja quanto à concessão da Ordem do Mérito Cultural, nem todos os mangueboys as encararam da mesma maneira. Renato Lins, jornalista, informalmente chamado de "ministro da Informação", devido a seu papel de elo com os jornais, tinha lá suas ressalvas em relação à questão da patrimonialização. Quando o entrevistamos, ele declarou:

\footnotetext{
2 Foram contemplados indivíduos e grupos do campo da música, do teatro, da música, das artes plásticas, da cultura popular, entre os quais Alfredo Bosi, crítico e historiador de literatura; Augusto Boal, diretor teatral; Aurino Quirino Gonçalves, Pinduca, cantor e compositor; Cleyde Becker Yáconis, atriz; Darcy Ribeiro, antropólogo, in memoriam; Eduardo Coutinho, cineasta; Egberto Gismonti, compositor e instrumentista; Eliane Lage, atriz; Henri Salvador, músico; Izabel Mendes da Cunha (do Vale do Jequitinhonha), artesã; João Gilberto, cantor e compositor; José Antônio de Almeida Prado, compositor erudito; José Mojica Marins, Zé do Caixão, cineasta; Maria Bethânia, cantora; Maurice Capovilla, cineasta; Manoel dos Reis Machado, Mestre Bimba, in memoriam; Militana Salustiano, cantora folclórica; Nei Lopes, cantor e compositor; Olivério Ferreira, Xangô da Mangueira, compositor; Roger Avanzi, palhaço Picolino do Circo Nerino; Ruth de Souza, atriz; Silviano Santiago, escritor; Vicente Joaquim Ferreira Pastinha, Mestre Pastinha, in memoriam, e Ziraldo Alves Pinto, cartunista (Cf.: BRASIL, 7/05/2013).
} 
Tornar patrimônio mumifica o negócio assim... Eu acho que hoje nós vivemos o tempo pós-Manguebeat. Nem o Recife, nem a indústria brasileira, nem a indústria da música, nem o Recife, nem nós. Nada é igual ao que era. As demandas são outras, os desejos, os pesadelos. [...] Tudo mudou e é evidente que surgiram outros desafios, outros sons. Claro que o Recife vive num contexto pós-Mangue [...] Mas eu acho uma homenagem meio desnecessária, banal (LINS, 9/10/2018).

É significativo o uso por Renato Lins da expressão "pósManguebeat", enunciadora de um distanciamento temporal e da delimitação entre passado e presente, que envolve as movimentações que ocorrem hoje na cidade. Mas sobre a Ordem do Mérito Cultural, sua opinião difere:

É o máximo reconhecimento em termo de cultura no Brasil. [...] Era a maior comenda. Com esse eu fiquei feliz e me permitiu conhecer Brasília; nunca tinha ido a Brasília. Fui com o Mundo Livre. O Mundo Livre foi fazer um show com a Nação Zumbi. Foi em 2006 [na realidade em novembro de 2005], no auge do mensalão, que considero a primeira tentativa de golpe no PT. Foi uma maneira de mostrar solidariedade pública a Lula. Fred [Zero Quatro] inclusive fez um show na cerimônia lá [...] Fred e Jorge [du Peixe] foram chamados para receber a comenda. O Mundo Livre na hora tocou aquela música "isso que dá, bicho de pé" [cantarolando trecho da canção "Édipo, o homem que virou veículo"] [...] depois teve um jantar a noite, que aí Lula não foi. Mundo Livre fez um show, o show foi de Mundo Livre. [...] Esse eu achei um reconhecimento justo, porque é um prêmio que tem critério e eu acho que o Mangue merecia (LINS, 9/10/2018).

Ao ser questionado sobre as semelhanças e diferenças entre as duas homenagens, Renato Lins falou, num caso, em aproveitamento político, engessamento do Manguebeat, enquanto, no outro, haveria um movimento em favor de sua afirmação e vivificação. Sobre a lei, o jornalista insiste:

É um aproveitamento político, com todo respeito a Sérgio Leite, deputado [...] que a propôs, mas eu achei uma forçação de barra. Ele não tinha nenhuma ligação com o Mangue. Por que aquele prêmio, naquela hora? Sei lá, não consigo explicar exatamente o porquê... [...]. Isso que me incomoda mais. A gente vive em tempos de pós-Mangue [...] Mas o Mangue em termo de som, de conceito etc. etc., acho que ele é bastante estimulante. [...] Tem tanta coisa embutida ali no Mangue que pode dar material, servir como inspiração (LINS, 9/10/2018).

Seja como for, quando o Manguebeat completou 25 anos em 2016 data definida a partir da primeira menção das movimentações das bandas no Jornal do Commércio em 1991 -, uma longa matéria foi publicada no site da Alepe e no jornal de circulação interna, o Tribuna Parlamentar (ZAHAR, 2016). Entrevistaram-se, então, alguns mangueboys como DJ Dolores, HD Mabuse, Renato Lins e Fred Zero Quatro. 0 tom da fala deles era praticamente o mesmo daquele proferido pelo deputado Sergio Leite na época da patrimonialização do Manguebeat. Para Mabuse, uma das consequências palpáveis dessa movimentação consistiu no fato de que "houve uma mudança na mentalidade das pessoas, com a percepção de que certas transformações estruturais podem ser realizadas na cidade. Antes do Mangue, para a indústria fonográfica, o Brasil ia até a Bahia. A gente conseguiu mudar essa geografia" (MABUSE apud ZAHAR, 2016). 
E, entre os feitos do Manguebeat, Mabuse termina por aludir, com justo orgulho, à sua conexão com o movimento Ocupe Estelita, que se fortaleceu em 2015 na luta contra a especulação imobiliária no Recife, a partir da ocupação do terreno da antiga Rede Ferroviária Nacional, localizado no Cais José Estelita, que durante meses causou um impasse envolvendo Prefeitura do Recife, construtoras e a Justiça. Esse movimento da sociedade civil, formado em sua maioria por jovens, propôs novas possibilidades para o uso daquele espaço público incrustado entre a zona sul e o centro da cidade (Cf.: BARBOSA, 2017). 0 Manguebeat, enfim, não era só música e entretenimento.

\section{O Memorial Chico Science: espaço de conexão passado e presente}

A Prefeitura do Recife desencadeou uma série de políticas públicas em relação ao patrimônio, memória e cultura, e, nesse processo, elaborou um discurso cultural baseado nas tradições, reinventando-as e adicionando a elas novos simbolismos, como ligados ao Manguebeat. A expressão "multicultural", por exemplo, passou a designar o Carnaval recifense e vários espaços e marcos foram criados como ancoradouros dessa visão de cultura que, ao entrelaçar o Estado e o mercado, atrelou-a a uma possibilidade de ganho econômico.

No caso do Manguebeat, uma das estruturas culturais concebidas pela política oficial foi o Memorial Chico Science (MSC), inaugurado em 24 de abril de 2009, síntese de uma relação cada vez mais próxima do presente e do passado. Tal ideia partiu da ex-namorada do artista, Maria Eduarda Belém, para quem foi feita a canção "Risoflora" (SCIENCE, 1994). De acordo com o material do antigo site do memorial, ele foi pensado como "um espaço dedicado a memórias, um lugar de reconstrução de histórias vividas. No entanto, pensar em conceituar um Memorial para Chico Science leva a um caminho que, começando no passado, também não poderia deixar de lado o por vir. Portanto, além do resgate do passado de Science, o memorial terá a fundamental função de levar a sua filosofia de reinvenção cultural adiante" (BELÉM, 2018).

Tratava-se, pois, de não só render homenagem a Chico Science como, igualmente, de veicular uma visão de cultura do Manguebeat a ser transmitida a outras gerações. Noutras palavras, "o memorial tem como função maior a preservação do acervo de Chico, não exatamente seus pertences, mas sua memória imaterial" (MOURA, in: JORNAL DO COMMERCIO, 24/04/2009). Calcado na perspectiva de "progresso", o MCS deveria ser "um local de permanente transformação" (MOURA, in: JORNAL DO COMMERCIO, 24/04/2009). Assim, ele atenderia ao propósito de tentar descolar o lugar da pecha de memória morta ou memória petrificada, em sintonia com o que já foi apontado, aqui, por Renato Lins.

O espaço remete, no fundo, a uma concepção exposta pelo próprio Chico Science na canção "Antromangue/Brasília", gravada posteriormente pela Nação Zumbi. A gravação começa com uma levada $d u b$, depois envereda para um estilo de um rock mais pesado. Diz-se que "a tecnologia do povo é a vontade", porém, nela ressoa uma espécie de nostalgia futurista: "Às vezes o mundo gira/ como um barulho que parece um motor de Brasília/ caminhando pelas ruas/ onde vejo o poder de um motor de Brasília" (NAÇÃO ZUMBI, 2000), misturada a 
uma crítica política. "Motor de Brasília" tem aqui um duplo papel: simboliza um motor de carro velho impulsionando as coisas e uma capital da República que caminha vagarosamente.

Tal espaço, por sua vez, visaria preencher uma dupla função: uma no mundo físico, outra no cyberspaço, conforme desejo de Chico Science. No primeiro, há uma linha do tempo com uma cronologia do Manguebeat e de Chico, guiando a entrada do visitante, contanto uma narrativa "oficial", apontando as primeiras festas, os lugares onde os mangueboys circulavam, com referências à gravação dos discos, aos shows e à cristalização da cena como parte da cidade. A curadora do projeto, Maria Eduarda Belém, ao descrever o local, com seus três ambientes, explicou que o primeiro se destinava a "apresentar a evolução de Chico até ele chegar a ser uma referência na música e na cultura pernambucana, e até nacional" (BELÉM, 2018).

Figura 1: Entrada do Memorial Chico Science no Pátio de São Pedro, centro do Recife.

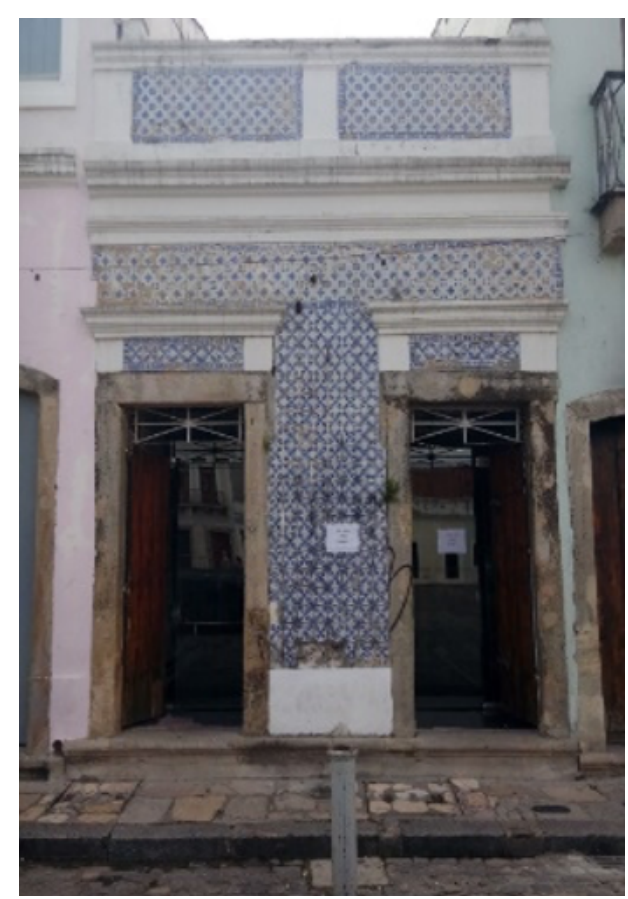

Fonte: autoria própria

Figura 2: Primeiro módulo do Memorial com uma exposição fixa contendo a cronologia do Manguebeat

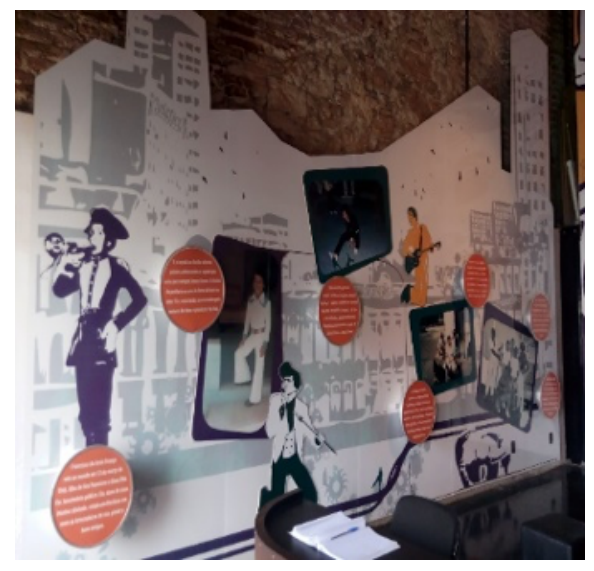

Fonte: autoria própria

Memorare, Tubarão, v. 8, n. 1, jan./jun. 2021. ISSN: 2358-0593 
A seguir, temos um espaço imersivo, composto por um projetor e um pufe. Nele, se assistem a documentários sobre o Manguebeat, nos quais se reafirma o discurso produzido pelos mangueboys sobre si mesmos, levando em conta um dos públicos-alvo prioritários do local, os turistas que afluem em grande número ao Pátio de São Pedro, onde o MCS se situa.

Enfim, como consta uma matéria da Folha de S. Paulo sobre o Antromangue, publicada dias após a morte de Chico Science e antes da gravação de "Antromangue/Brasília", ele previa para um futuro não muito distante, a criação de um espaço especial: "A Antromangue teria entre outras coisas um estúdio e uma escola de música. Ela seria localizada no centro histórico da cidade. E apoiaria pesquisas sobre ritmos e tradições locais, artes plásticas, teatro e literatura. A homepage traria textos escritos por ele sobre o movimento mangue beat, manuscritos de algumas músicas" (SANTIAGO, in: FOLHA DE SÃO Paulo, 4/2/1997).

0 artista discorria ainda sobre uma novela a ser lançada na internet, baseada numa trama distópica. Nesse lugar físico, produtor de cultura, os valores que impulsionavam o Manguebeat seriam disseminados, colocando em circulação todos os simbolismos vinculados ao mangue. Na inauguração do MCS, o secretário de Cultura Renato Lins lembrou que "o Memorial põe em prática um sonho antigo de Chico que era o Antromangue, um núcleo onde se promoveria a difusão de conhecimentos musicais, literatura, cinema e cultura popular" (LINS apud RECIFE, 28/4/2009).

No caso específico do MCS, versão materializada do Antromangue, foi guiado pela ideia de um espaço de salvaguarda da memória da cena, mas também como um local conectado ao presente e que aparece na afirmação do então prefeito João da Costa (PT): “A proposta do Memorial é de algo vivo, que trabalhe a contemporaneidade da música pernambucana" (COSTA apud RECIFE, 28/4/2009). Na sua inauguração, Jorge du Peixe e Lúcio Maia, parceiros de Chico na Nação Zumbi, apresentaram o som eletrônico do projeto já finalizado projeto Cool Crabs. Além deles, o artista gráfico Galo de Souza foi responsável por projeções de grafite ao vivo nas paredes do memorial.

A instalação do MCS implicou um custo de 305 mil reais. Localizado em um casarão erguido numa das regiões mais antigas da região central, o Pátio de São Pedro, está ao lado da famosa Igreja de São Pedro e de outros aparelhos culturais da prefeitura, como o Memorial Luiz Gonzaga e o Conselho de Cultura da Cidade do Recife. De todo modo, em entrevista que nos concedeu, o ex-secretário de Cultura Renato Lins reconheceu as limitações do memorial: "[O MCS] Não foi pensando para armazenar um grande acervo físico, até por questões de tamanho. A ideia era você ter um armazenamento de informações básicas sobre o Manguebeat na internet, pra pesquisadores, turistas e curiosos etc., e de fazer daquilo um pequeno centro de reflexão sobre a música. Então quando eu assumi [como secretário de Cultura na administração de João da Costa] foi nessa linha que a gente prosseguiu" (LINS apud RECIFE, 28/4/2009).

E, nessa linha, Renato Lins relatou algumas atividades que ocorriam no local:

Memorare, Tubarão, v. 8, n. 1, jan./jun. 2021. ISSN: 2358-0593 
Foram anos em que, com minha concordância, claro, a Adriana Vaz, esposa de H. D. Mabuse [um dos amigos de Chico Science, que junto com ele criou projetos musicais que ajudaram na formatação das canções e da Nação Zumbi, posteriormente] [...] explorou muito a relação da arte com a tecnologia, que era um tema da hora. Teve muita oficina em torno disso. E a gente criou uma semana, que era a Semana Chico Science, na semana em que Chico nasceu, em março. A gente meio que copiou um festival que eu esqueci o nome, que a cada ano eles convidam um artista e entregam a curadoria para esse artista; a gente passou a fazer isso. No primeiro encontro a gente chamou Alex Antunes, que é um jornalista de São Paulo. Entregamos a curadoria a Alex para ele ter liberdade para pensar um tema que de alguma forma dialogasse com o Mangue, mas que fosse contemporâneo (LINS apud RECIFE, 28/4/2009).

Isso tudo se casava, assim, com as intenções declaradas de Maria Eduarda Belém, para quem "a ideia é transformar o Memorial Chico Science não só num lugar onde a sua história é preservada, como também numa célula de incentivo à produção, onde a principal matériaprima para isto é fornecida: informação" (BELÉM, 2018).

Nos documentos e materiais da Prefeitura da Cidade do Recife, aos quais tivemos acesso, são descritos alguns eventos do MCS. Buscou-se, até certo ponto, passar da intenção para a ação. Uma das primeiras realizações do memorial consistiu numa exposição de camisas, que fugia à diretriz mais específica de produção de cultura. 0 foco, no caso, foi a memória do próprio Manguebeat, com ênfase nas estampas de bandas, festivais ou shows. A mostra se chamou Camiseta Sonora. Em matéria inserida no Diário Oficial da Prefeitura, Renato Lins justificou: "As peças resgatam a lembrança de um período muito importante para a cultura da cidade, quando a criatividade e vitalidade tomaram proporções pouco vistas no Brasil" (LINS apud RECIFE, 20/10/2018).

Outros eventos seguiram a tônica de lembrar algo associado às bases do Manguebeat. Em 2009, a gestora do MCS, Adriana Vaz, anunciou a criação de uma espécie de clube de leitura de ficção científica, concebido pelo artista plástico Jarbas Jácome. A ideia era incentivar o debate sobre esse tipo de literatura e ainda alimentar o acervo do local, pois as pessoas poderiam fazer doações (RECIFE, 21/10/2018).

Como se sabe, a ficção cientifica é um tema recorrente na produção do Manguebeat. Nas letras e melodias das canções há citações sobre tal literatura a esse tipo de literatura, da mesma forma que no texto Caranguejos com cérebro. Uma das canções da Chico Science \& Nação Zumbi que mais explicita essa relação é "O encontro de Isaac Azimov com Santos Dumont no céu":

Nada como o firmamento

Para trazer ao pensamento

A certeza de que estou sólido

Em toda a área que ocupo

E a imensidão aérea

É ter o espaço do firmamento

No pensamento

E acreditar em voar algum dia (SCIENCE, 1996).

Aqui fala mais alto o sonho de voar contado de forma poética, com o toque da psicodelia. São, nas palavras de Fred Zero Quatro, os tais "avanços da química aplicados no térreo da alteração e expansão da 
consciência" (ZERO QUATRO, 1994). A ficção científica, por sua capacidade de projetar um mundo diferente, utópico ou distópico, serviu de inspiração para algumas canções do Manguebeat, quando mais não seja porque, como se lê em Caranguejos com cérebro, "os mangueboys e manguegirls são indivíduos interessados em hip hop, colapso da modernidade, caos" (ZERO QUATRO, 1994). Aliás, em um dos compartimentos do MCS, há uma pequena biblioteca que contém desde quadrinhos como Sandman, de Neil Gaiman, livros de Josué de Castro, como Geografiada fome e Homens e caranguejos, e Admirável mundo novo, de Aldous Husley, considerado uma das maiores referências do campo da literatura de ficção científica, bem como As crônicas marcianas, de Ray Brandbury.

O espaço do memorial também foi usado durante outros eventos. Duas edições do Coquetel Molotov utilizaram a estrutura para oficinas e outros acontecimentos ligados ao festival. Em 2010, tiveram lugar, por exemplo, a oficina de música "Anatomia de um Soundsystem", com Russo Parapusso, vocalista da banda Baiana System, e Chico Correia, e a oficina "Murais urbanos: técnicas de criação", com Stephen Calma, um designer gráfico. Em 2011, o MCS sediou a mostra "Filosofias musicais músicas traduzidas em imagens" que foi, basicamente, o resultado de uma oficina ministrada pelo artista de grafite Derlon (Cf.: EXPOSIÇÃO ABERTA NO MEMORIAL CHICO SCIENCE, 27/11/2011). Neste caso, estabeleceu-se uma relação próxima entre um aparelho público, o memorial, e a iniciativa privada, a exemplo de parcerias firmadas em outros momentos.

Durante a administração petista, a cultura, cada vez mais, tornou-se um negócio lucrativo. Segundo George Yúdice, em texto escrito em 2004, "a cultura está sendo crescentemente dirigida como um recurso para a melhoria sociopolítica e econômica, ou seja, para aumentar sua participação nessa era de desenvolvimento político decadente, de conflitos acerca da cidadania" (YÚDICE, 2004, p. 25). Para atingir tal objetivo, seria necessário seu gerenciamento racional, alicerçado em estratégias definidas no âmbito das políticas públicas. Nesse sentido, "a cultura [aparece] como uma esfera crucial para investimentos, a cultura e as artes são cada vez mais tratadas como qualquer outro recurso [...] catalisadora[s] do desenvolvimento humano" (YÚDICE, 2004, p. 30). Essa visão se expressou, por exemplo, nas oficinas ministradas em 2010 no Festival no Ar: "Transmissões on-line: como realizar webcasts ao vivo", "Remixando: criando novas músicas com loops e beats", "Tecnomelody: das aparelhagens aos batidões", "Murais urbanos: técnica de criação" e "Anatomia de um sound system: improvisação com rimas, sons e delas" (Cf.: RECIFEROCK, 10/8/2010). Davam-se as mãos, assim, cultura e tecnologia, paralelamente à junção da afirmação de aspectos simbólicos e oportunidade econômica ou abertura de espaço no mercado.

Como já mencionado, a Semana Chico Science fora criada para celebrar todos os anos o nascimento do "malungo". Em 2012, para selar a convivência entre cultura e tecnologia, o tema transversal foi música e ciberativismo no mundo contemporâneo e contou com a curadoria de Ricardo Brazileiro e Ricardo Ruiz, da 3ecologias.net, consultores de inovação digital (Cf.: TERCEIRA EDIÇÃO DA SEMANA CHICO SCIENCE..., 
18/3/2012). Ocorreram oficinas sobre ciberativismo, comunicação nas periferias e até gastronomia, com experimentalismos alimentares, tendo como tema o Manguebeat. A então gestora do memorial, Adriana Vaz, insistia na ideia-motriz na qual a instituição se apoiava: "Desde que foi criado, o Memorial Chico Science pretende ser um laboratório que oferece ao público formação e intervenções que unem tecnologia e cultura. Por isso, pela terceira vez estamos aqui pra fazer um mergulho em um dos vieses dessa temática" (VAZ apud RECIFE, 21/3/2012).

Por outro lado, em sintonia com a política oficial de turismo do governo João da Costa, em 2012, o MCS sediou um dos eventos da "Conheça o Recife": o "Circuito da Música e seus influentes pernambucanos" (RECIFE, 17/10/2012). Tal projeto da Secretaria de Turismo promovia passeios guiados. Esse, em especial, privilegiava lugares que tinham alguma conexão com a história e a produção musical da cidade. Naquele ano, os locais escolhidos foram: o Memorial Chico Science, o Memorial Luiz Gonzaga, o Conservatório Pernambucano de Música e o Sesc de Casa Amarela, onde existe um importante acervo da memória da música pernambucana. Outros passeios também eram realizados pela prefeitura, como o que percorria o Circuito da Poesia.

No que diz respeito ao MCS, ainda convém, frisar que ele dá curso a preocupações de ordem mais estritamente pedagógicas. Por ser um espaço público, vinculado à Prefeitura da Cidade do Recife, ele abre visitas a estudantes, como em 2012, quando recebeu alunos da Escola Municipal Nadir Colaço, do bairro da Macaxeira, da Zona Norte, na esteira de um projeto de um docente sobre o cantor (Cf.: RECIFE, 12/12/2012). Conforme o professor Ronald Santana, "o projeto surgiu porque aqui na escola temos várias salas temáticas, uma delas, em homenagem a Chico" (SANTANA apud RECIFE, 12/12/2012). Por sinal, Chico Science já havia sido uma das temáticas escolhidas pela Secretaria de Educação do município para o ano letivo de 2003.

\section{${ }_{4} \mathrm{O}$ site do Memorial Chico Science como lugar de memória virtual}

O caráter pedagógico do MCS se explicita de forma inequívoca em seu site institucional. Apesar de a Prefeitura da Cidade do Recife não haver cuidado de mantê-lo ativo, ele, seja como for, continua no ar, mesmo que com dificuldades de acessá-lo.

Figura 3: Capa do antigo site do Memorial Chico Science.

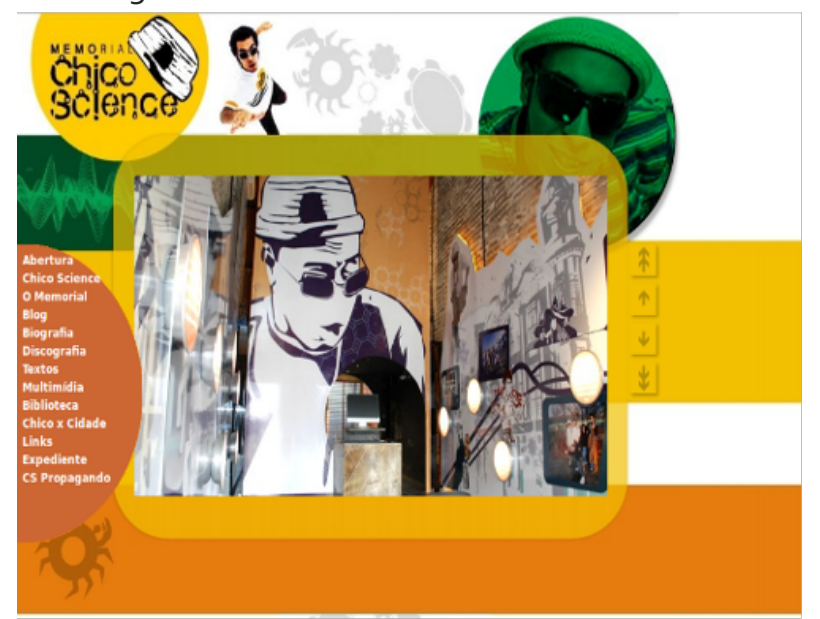

Fonte: Print da tela inicial

Memorare, Tubarão, v. 8, n. 1, jan./jun. 2021. ISSN: 2358-0593 
O objetivo que o justificou era o de recriar o espaço físico do memorial no ambiente virtual, materializando uma ideia de Chico Science: o estabelecimento de uma interface entre tal aparelho e as redes computacionais. Dessa maneira, além da apresentação institucional do memorial, o site se propunha a ser um elemento propagador da narrativa do Manguebeat. No print acima são visíveis dois dos seus ícones imagéticos: o caranguejo, como marca d'água e a imagem de Chico. Na logomarca do MCS, vemos o famoso chapéu acima do nome do cantor, e a fonte utilizada lembra os conectores dos chips. Os caranguejos aparecem atrelados a engrenagens, dando uma ideia de movimento e de tecnologia. Percebe-se que o conteúdo disponível desse lugar de memória foi pensado para ser uma versão virtual do museu. ${ }^{3}$

Nesse acervo digital foram reunidos, obviamente, escritos dos principais personagens ligados a Chico Science e ao Manguebeat. Renato Lins, por exemplo, assina um texto no qual expõe "estilhaços" da memória, ao se reportar ao "Manguebeat: breve histórico do seu nascimento" (LINS, in: RECIFE). Depois de admitir que "cada um interpreta os fatos de maneira diferente, cada memória remixa o que ficou para trás de um jeito todo seu" e que, "por conta disso [...] parece impossível determinar exatamente como o Mangue nasceu", ele segue pontuando nomes, como o de Fred Zero Quatro, H. D. Mabuse e, claro, Chico Science: "Cada estilhaço dessas vidas foi marcado por uma paixão pela música e uma insatisfação com o que era produzido no Brasil em termos de cultura pop" (LINS, in: RECIFE). A linha mestra que conduz o discurso sobre a história do Manguebeat está ali. Os mesmos elementos lançados pelos textos de Zero Quatro, Caranguejos com cérebro e Quanto vale uma vida?, considerados "manifestos" da cena e que também estão disponíveis no site, reaparecem nas palavras de Renato $\mathrm{L}$.

Como conteúdo disponibilizado no portal temos um histórico sobre o Manguebeat em formato resumido e acessível a um público maior. Sob o título "Glossário", uma das seções do website apresenta os principais personagens, obras, eventos e espaços que, de alguma maneira, traçaram o roteiro memorialístico. São citados, por exemplo, sob a denominação "Manifestos", dois textos matriciais de autoria de Fred Zero Quatro, um de 1992 e outro de 1997. 0 primeiro remonta às primeiras festas e shows em lugares decadentes do Recife Antigo:

Primeiro Manifesto - Zero Quatro é o autor do chamado Primeiro Manifesto Mangue. 0 texto, escrito em 92, deveria funcionar apenas como um release. Na época, o Mundo Livre e Chico Science e Nação Zumbi haviam realizado alguns shows em conjunto e um certo frisson em torno do Mangue rolava pela cidade, principalmente entre os formadores de opinião pública. 0 release acompanharia uma espécie de book do Mangue, com recortes de jornais, cartazes e panfletos, a ser enviado à mídia e às gravadoras. Mas o estilo da escrita do Zero, bastante incomum para esse

\footnotetext{
3 Observa-se hoje uma discussão sobre a virtualização dos espaços patrimoniais e sobre como novas formas de interação com os espaços museais podem surgir. 0 Google, por exemplo, tem a plataforma Arts\&Culture, em colaboração com museus do mundo todo, disponibilizando parte do acervo dessas instituições virtualmente. Sobre memória e mundo digital, ver: HENRIQUES, Rosali Maria Nunes. Narrativas, patrimônio digital e preservação da memória no Facebook. Revista Observatório, v. 3, Palmas, 2017. De acordo com Levy, "o ciberespaço [...] é o novo meio de comunicação que surge da interconexão mundial dos computadores. 0 termo especifica não apenas a infraestrutura material da comunicação digital, mas também o universo oceânico de informações que ela abriga, assim como os seres humanos que navegam e alimentam esse universo" (LÉVY, 1999, p. 17). A propósito, sobre o trabalho do historiador e os meios virtuais (ALMEIDA, in: AEDOS, 2011).
} 
tipo de texto, influenciou na sua recepção, transformando o

despretensioso release no "primeiro manifesto". Nas suas três partes (O Conceito, A Cidade e A Cena) um fato mostra-se fundamental: foi graças a um trabalho sobre os manguezais realizado para uma produtora independente do Recife, a TV Viva, que Zero - um jornalista, vale lembrar - reuniu as informações sobre o ecossistema Mangue utilizadas no texto (GLOSSÁRIO, in: RECIFE).

Aqui se assume abertamente que Caranguejos com cérebro foi um "manifesto", mesmo fazendo-se a ressalva que deveria funcionar como um release. 0 "segundo manifesto" foi, talvez, pensado como tal e publicado dias após a morte de Chico.

Segundo Manifesto - Publicado no Jornal do Commercio em março de 97, logo após o acidente que vitimou Chico Science, esse texto surgiu com a missão de sinalizar a sobrevida do Mangue e da Nação Zumbi à morte do seu maior ídolo. Escrito por Zero Quatro com a ajuda de Renato L, o manifesto proclamou a continuidade do movimento e listou as qualidades que faziam da Nação mais do que uma mera banda de apoio e, por isso, possuidora das condições necessárias para continuar suas atividades. Mais jornalístico que o primeiro e de menor repercussão, sua importância, no entanto, não deve ser subestimada: numa hora em que todos pareciam perdidos e atônitos, foi através dele que Zero Quatro e Renato L

enfatizaram uma posição comum ao núcleo-base do movimento numa hora decisiva (GLOSSÁRIO, in: RECIFE).

De um modo geral, o "glossário" vale como um texto introdutório, seguindo a narrativa oficial que o Manguebeat erigiu para si como movimento. Isso se aplica igualmente ao texto "Biografia", de Renato Lins, que lista em ordem cronológica os fatos considerados mais relevantes na vida de Chico Science, instituindo, portanto, a partir dos marcos selecionados, uma personalização da cena: Chico. Science é o Manguebeat, o Manguebeat é Chico Science. Na linha narrativa de L, o mangueboy olindense aparece como elemento integrador, aquele que uniu os diversos grupos atuando como um mediador cultural entre a periferia e o centro, Peixinhos e Candeias, o hip hop e o maracatu, passando pelo rap, até desaguar nas alfaias. Chico é colocado no entrelugar, na fronteira entre os ritmos, as classes sociais. $\mathrm{O}$ artista, afinal, era dado a deglutir diferentes informações:

Em 92, Chico Science, Zero Quatro e Mabuse dividiram um amplo apartamento na rua da Aurora. 0 prédio, chamado Capibaribe, possuía cômodos imensos, com uma sala de alguns "quilômetros" que terminava num amplo janelão. Dali era possível avistar o porto do Recife e quase todas as pontes sobre seus rios. No chão dessa sala imensa Chico recebia os amigos que vinham pra conversar, beber cerveja e escutar desde as atormentadas canções do trovador Nick Cave até os singelos vocais do jornalista Cadão Volpato na banda paulista Fellini (LINS, in: RECIFE).

Esse tipo de registro biográfico contribuiu, sem dúvida, para fomentar uma aura especial em torno de Chico Science, de resto reforçada pela imprensa e pelo poder público. Tal símbolo, reiterado na seleção de memórias do MCS para Chico, dá continuidade, em última análise, a um processo iniciado pelo próprio músico em suas performances no palco, vestido às vezes, como já vimos, de caboclo de lança ou de um personagem de cavalo-marinho, cantando de um jeito que ora lembrava um rapper ora um embolador. A figura de Chico 
despontou, assim, criada como um sujeito de fronteiras, simbolizando o ideário de fusão musical do Manguebeat.

\section{Considerações finais}

Entre 1997 e 2012, ocorreu, a nosso ver, um processo de legitimação de uma narrativa sobre o Manguebeat que tomou como ponto de partida a produção das suas duas principais bandas e a morte de Chico Science. Tal fato ajudou a fomentar uma série de práticas culturais no Recife sob o estímulo, entre outros, do poder público e da imprensa. Intensificou-se, então, a circulação de determinados símbolos que incrementaram um imaginário sobre a capital pernambucana, respaldado, por exemplo, pelos grafites presentes nos muros da cidade. Com o passar do tempo, a proximidade do poder público municipal e do Manguebeat resultou na celebração de certas efemérides e na criação de lugares de memória que englobaram também a iniciativa privada, em relação ao Mangue e ao legado do cantor morto em 1997.

Esse processo não se encerrou em 2012, com a saída do PT da Prefeitura do Recife. Já em 2015, após reuniões noticiadas com algum alarido pela imprensa recifense, o grupo de trabalho que envolveu representantes do governo municipal e estadual (secretários de Cultura do município e do estado), da família de Chico Science (sua filha) e da banda Nação Zumbi (Jorge du Peixe) apresentou um calendário de comemoração de datas importantes para o Manguebeat. Thayná Louise lembrou o Memorial Chico Science vivia uma situação de abandono. Foi, então, prometida uma reforma no lugar e até cogitado levá-lo para outra área, ao lado da Cruz do Patrão e do Forte do Brum, no Recife Antigo, ideia que, no entanto, caiu no esquecimento. De mais a mais, numa demonstração de que o preito de reconhecimento que se rende ao cantor esbarra em limites igualmente muito significativos, a reforma anunciada no Memorial continua por fazer.

Contudo, reiteramos, no que diz respeito ao Memorial, que ele passa por uma situação difícil nestes últimos anos. Até 2012, quando terminou a administração municipal petista, o local recebia maior atenção, diferentemente do tratamento que lhe é dispensado (ou melhor, não dispensado) na gestão Geraldo Júlio, do PSB. Algumas matérias jornalísticas, quando não uma simples visita ao MSC, são eloquentes para atestar o seu abandono. Seus equipamentos acham-se parcialmente deteriorados. Além do mais, quem chega ao Pátio de São Pedro e procura o casarão onde funciona o memorial tem dificuldade de encontrá-lo. A rigor, a maioria dos transeuntes sequer sabe onde ele se situa. Se o visitante se aproxima do número 21, verá nas portas de vidro um papel A4 com os dizeres Memorial Chico Science impressos. No interior do MCS, nas vezes em que o visitamos, o espaço "imersivo" mantinha a TV desligada: ele se tornara apenas uma sala escura com uma grande almofada no chão. Noutra dependência, como se não bastasse o mofo na parede, há uma biblioteca que parou no tempo: ela continua com estrutura similar a de 2012, reduzida a cerca de 70 livros. Um estagiário - e só um - recebe os visitantes, que, a julgar pelos nomes listados no caderno de visitas, são em número diminuto.

Tal situação desalentadora chamou a atenção da página do Faceboock Raízes do Mangue, no Facebook, hoje em dia desativada. Em 
2015, o líder do grupo, Almir Cunha, convocou cerca de 500 pessoas ligadas a ele para uma reunião na Rua da Aurora, debaixo da estátua do caranguejo, para cobrar do poder público mais cuidado com o memorial. Esse encontro resultou em uma carta, enviada à Secretaria de Cultura do município, à qual o memorial se vincula. Enfatizou-se que o abandono não afeta tão somente o MCS, mas todos os aparelhos culturais localizados no Pátio de São Pedro, como o Memorial Luiz Gonzaga, a Casa do Carnaval, o Núcleo de Cultura Afro, o Centro de Design e até o prédio do Conselho de Cultura. Justo o pátio que foi pensado pela administração petista como centro de atração turística, baseado no princípio da diversidade e ancorado nas figuras de Chico, Gonzaga e do legado do carnaval, além da Igreja de São Pedro, em princípio um grande atrativo para turistas. Porém, a partir da gestão Geraldo Júlio e de seus constantes cortes de pessoal e de gasto público, esses aparelhos vêm funcionando parcial e precariamente, exceto a Igreja, que, obviamente, não é da alçada da Prefeitura e acabou de ser reaberta depois de restaurada. Lamentavelmente, isso tudo remete a descontinuidades das políticas públicas relativas à cultura, um traço comum a muitos governos brasileiros.

\section{Referências}

ALBERTI, Verena. Histórias dentro da História. In: PINSKY, Carla Bassanezi (org.). Fontes históricas. São Paulo: Contexto, 2015.

ALMEIDA, Fábio Chang de. 0 historiador e as fontes digitais: uma visão acerca da internet como fonte primária para pesquisas. Aedos, v. 3, n. 8, Porto Alegre, jan./jun. 2011. Disponível em: <https://seer.ufrgs.br/aedos/article/view/16776/11939>. Acesso em: 20 out. 2018.

BHABHA, Homi. 0 lugar da cultura. Belo Horizonte: Editora UFMG, 2013.

BARBOSA, D. T. Ocupe Estelita: fé, palavras e ações na política urbana da cidade do Recife. Anais do XVII ENANPUR (Encontro Nacional da Associação Nacional de PósGraduação e Pesquisa em Planejamento Urbano e Regional), São Paulo. São Paulo: 2017.

BELÉM, Maria Eduarda. 0 memorial. Disponível em: <http://www.recife.pe.gov.br/chicoscience/memorial.html>. Acesso em: 20 out. 2018.

BRASIL. Parque Memorial Quilombo dos Palmares. 0 memorial. Palmeiras dos Índios/AL. Disponível em <http://serradabarriga.palmares.gov.br/?page_id=101>. Acesso em 17 nov. 2018.

BRASIL. Ministério da Cultura. Ordem do mérito cultural 2005. Brasília, 7 maio 2013. Disponível em: <http://www.cultura.gov.br/ordem-do-merito-cultural2005>. Acesso em: 16 nov. 2018.

BRASIL. Câmara dos Deputados. Discursos e notas taquigráficas. Brasília, 10 nov. 2005. Disponível em:

<http://www.camara.leg.br/internet/sitaqweb/TextoHTML.asp?etapa=5\&nu Sessao $=302.3 .52 .0 \&$ nuQuarto $=64 \&$ nuOrador $=2 \&$ nuInsercao $=0 \&$ dtHorarioQu arto $=16: 06 \&$ sgFaseSessao $=$ GE\&Data $=10 / 11 / 2005 \&$ txApelido $=$ PAULO $\% 20$ RU 
BEM\%20SANTIAGO,\%20PT-

PE\&txFaseSessao=Grande\%20Expediente\&txTipoSessao=0rdin $\%$ C3\%A1ria\% 20-\%20CD\&dtHoraQuarto=16:06\&txEtapa=>. Acesso em: 14 nov. 2018.

CANDAU, Joël. Memória e identidade. São Paulo: Contexto, 2016.

CEBALLOS, Viviane Gomes de. "E a história se fez cidade...”: a construção histórica e historiográfica de Brasília. Dissertação (Mestrado em História) - Unicamp, Campinas, 2005.

CHAUI, Marilena. Brasil: mito fundador e sociedade autoritária. São Paulo: Perseu Abramo, 2000.

CHICO Science \& Nação Zumbi. Da lama ao caos. Chaos/Sony, 1994.

CHICO Science \& Nação Zumbi. Afrociberdelia. Chaos/Sony, 1996.

CHOAY, Françoise. A alegoria do patrimônio. São Paulo: Editora da Unesp/Estação Liberdade, 2006.

ELIAS, Aluf Alba Villar. Arquivo, verdade e o processo de transição democrática no Brasil: o legado da Comissão Nacional da Verdade para ampliação da discussão epistemológica arquivística. Doutorado (Ciências da Informação) UNB, Brasília, 2018.

FACEBOOK. Raízes do Mangue. Disponível em: <https://www.facebook.com/raizesdomanguerec>. Acesso em: 21 out. 2018.

EXPOSIÇÃO aberta no Memorial Chico Science. Recife, 27 nov. 2011. Disponível em: <http://coquetelmolotov.com.br/novo/exposicao-aberta-no-memorial-chicoscience>. Acesso em: 20 out. 2018.

HARTOG, François. Regimes de historicidade: presentismo e experiências do tempo. Belo Horizonte: Autêntica, 2013.

HENRIQUES, Rosali Maria Nunes. Narrativas, patrimônio digital e preservação da memória no Facebook. Observatório, v. 3, Palmas, 2017.

HUYSSEN, Andreas. Seduzidos pela memória. Arquitetura, monumentos, mídia. Rio de Janeiro: Aeroplano, 2000.

LE GOFF, Jacques. História e memória. Campinas: Editora Unicamp, 1990.

LEÃO, Fabiana de Souza. 0 fenômeno pós-mangue na cena musical pernambucana. Dissertação (Mestrado em Administração) - UFPE, Recife, 2007.

LÉVY, Pierre. Cibercultura. São Paulo: Editora 34, 1999.

LINS, Renato. Entrevista concedida a este pesquisador. Recife, 9 out. 2018.

"MANGUETRONIC" traz inéditas de Science. Folha de S. Paulo, Ilustrada, São Paulo, 17 fev. 1997. Disponível em:

<https://www1.folha.uol.com.br/fsp/1997/2/17/ilustrada/41.html>. Acesso em: 25 out. 2018.

MOURA, Luís Fernando. Recife agora tem Memorial Chico Science. Jornal do Commercio, Caderno C. Recife, 24 abr. 2009, p. 8. 
MUNDO Livre S/A. Carnaval na obra. Abril, 1998.

NAÇÃO Zumbi. Rádio S.amb.a: serviço de afrociberdelia. YB Music, 2000.

NORA, Pierre. Entre história e memória: a problemática dos lugares. Projeto História, v. 10, São Paulo, 1993.

PERNAMBUCO. Assembleia Legislativa do Estado de Pernambuco. Lei № 13.853, de 19 de agosto de 2009. Recife, 19 ago. 2009. Disponível em: <http://legis.alepe.pe.gov.br/texto.aspx?id=169\&tipo=TEXTOORIGINAL>. Acesso em: 14 nov. 2018.

PERNAMBUCO. Assembleia Legislativa do Estado de Pernambuco. Manguebeat, de Pernambuco para o mundo. Recife, 8 dez. 2009. Disponível em: <http://www.alepe.pe.gov.br/2009/12/08/manguebeat-de-pernambucopara-o-mundo/>. Acesso em: 14 nov. 2018.

RECIFE. Prefeitura do Recife. Diário Oficial. Memorial Chico Science é inaugurado no Pátio de São Pedro. Recife, edição 28 abr. 2009. Disponível em:

$<$ http://www.recife.pe.gov.br/diariooficialacervo/exibemateria.php?cedicacodi $=48 \&$ aedicaano $=2009 \&$ ccadercodi $=1 \& \mathrm{cs}$ ecaocodi $=1 \&$ cmatercodi $=2 \& Q P=$ chico + science $\& T P=>$. Acesso em: 18 de out. 2018.

RECIFE. Prefeitura do Recife. Diário Oficial. Estampas em tecido no Memorial Chico Science. Recife, edição 116, 10 out. 2009. Disponível em:

$<$ http://www.recife.pe.gov.br/diariooficialacervo/exibemateria.phpcedicacodi $=116 \&$ aedicaano $=2009 \&$ ccadercodi $=1 \&$ cs ecaocodi $=1 \&$ cmatercodi $=4 \& Q P=$ chico + science $\& T P=>$. Acesso em: 20 out. 2018.

RECIFE. Prefeitura do Recife. SILVA, Marcos da. Estudantes da Escola Nadir Colaço montam projeto biográfico sobre Chico Science. Recife, 12 dez. 2012. Disponível em:

<http://www2.recife.pe.gov.br/noticias/12/12/2012/estudantes-da-escolanadir-colaco-montam-projeto-biografico-sobre-chico-science >. Acesso em: 24 out. 2018.

RECIFE. Prefeitura do Recife. LINS, Renato. Manguebeat. Breve histórico do seu nascimento. Recife, s./d. Disponível em:

$<$ http://www.recife.pe.gov.br/chicoscience/textos_renatol3.html>. Acesso em: 23 out. 2018.

RECIFE. Prefeitura do Recife. Glossário. Mangue de A a Z. Disponível em: http://www.recife.pe.gov.br/chicoscience/textos_glossario.html. Acesso em: 26 out. 2018.

RECIFE. Prefeitura do Recife. Conheça o Recife realiza circuito musical. Recife, 17 out. 2012. Disponível em: <http://www2.recife.pe.gov.br/noticias/17/10/2012/conheca-o-reciferealiza-circuito-musical>. Acesso em: 23 out. 2018.

RECIFE. Prefeitura do Recife. LINS, Renato. Biografia. Memorial Chico Science. Disponível em: <http://www.recife.pe.gov.br/chicoscience>. Acesso em: 26 out. 2018.

RECIFE. Prefeitura do Recife. SOBRINHO, Janaína. Começa terceira edição da Semana Chico Science. Recife, 21 mar. 2012. Disponível em: 
<http://www2.recife.pe.gov.br/noticias/21/03/2012/comeca-terceiraedicao-da-semana-chico-science>. Acesso: em 20 out. 2018.

RECIFE. Prefeitura do Recife. Memorial Chico Science abre espaço para ficção científica. Recife, 21 out. 2009. Disponível em: <http://www.recife.pe.gov.br/2009/10/21/memorial_chico_science_abre_esp aco_para_ficcao_cientifica_169062.php>. Acesso em: 20 out. 2018.

SAITO, Bruno Yutaka. Festival mergulha no pós-Mangue de Pernambuco. Folha de S. Paulo. São Paulo, 18 set. 2002. Disponível em: $<$ https://www1.folha.uol.com.br/fsp/acontece/ac1809200201.htm>. Acesso em: 18 out. 2018.

SAIU a programação do Festival no Ar 2010. RecifeRock!. Recife, 19 ago. 2010. Disponível em: <http://www.reciferock.com/2010/08/19/saiu-a-programacao-dofestival-no-ar-2010/>. Acesso em: 20 out. 2018.

SANTIAGO, Wanderck. Chico Science planejava novela na Internet. Folha de S. Paulo, Ilustrada, São Paulo, 4 fev. 1997.

TERCEIRA edição da semana Chico Science conta com debates shows. Recife, 18 mar. 2012. Disponível em: <http://coquetelmolotov.com.br/novo/terceira-edicaoda-semana-chico-science-conta-com-debates-e-shows $>$. Acesso em: 20 out. 2018.

YÚDICE, George. A conveniência da cultura: usos da cultura na era global. Belo Horizonte: Editora UFMG, 2004.

ZAHAR, André. Raízes conectadas. Tribuna Parlamentar, ano XVI, n. 153, Recife, nov., 2016. Disponível em: <http://www.alepe.pe.gov.br/Flip/pubs/tribunaparlamentar-9/flip.pdf>. Acesso em: 17 nov. 2018.

Artigo enviado em: 24/10/2020. Aprovado em: 19/04/2021. 